\title{
Uma análise de discurso de base enunciativa: notas de leitura sobre o percurso epistemológico de Dominique Maingueneau ${ }^{1}$
}

\author{
An enunciative discourse analysis: notes on the epistemological path of Dominique \\ Maingueneau
}

$\begin{array}{r}\text { Roberto Leiser Baronas } \\ \end{array}$
Universidade Federal de São Carlos - UFSCar
Conselho Nacional de Desenvolvimento Científico e Tecnológico - CNPq
Samuel Ponsoni $^{3}$
Universidade do Estado de Minas Gerais - UEMG
Campus de Passos

RESUMO: Neste texto, buscamos apresentar de maneira não exaustiva o percurso teórico-metodológico do discursivista francês Dominique Maingueneau acerca de uma análise de discurso de base enunciativa. Dividimos a nossa intervenção em dois momentos. No primeiro, apresentamos muito rapidamente o que seriam as cinco ideias-força desenvolvidas por Maingueneau ao longo de seu percurso acadêmico, a saber: 1) Semântica Global; 2) Cenas da Enunciação; 3) Discursos Constituintes: o discurso literário; 4) Enunciação Aforizante e 5) A Filosofia como instituição discursiva. No segundo momento, buscamos mostrar como essa última ideia-força, ainda em desenvolvimento por Maingueneau, pode iluminar outras pesquisas no campo do discurso brasileiro, sobretudo no âmbito da linguística brasílica. Ilustra essa possibilidade uma proposta de trabalho discursivo sobre os escritos do linguista brasileiro Mattoso Câmara Jr.

Palavras-chave: Discurso; Epistemologia dos estudos discursivos; Linguística brasileira.

\begin{abstract}
In this text, we try to present in a non-exhaustive way the theoretical-methodological path of the French discursivist Dominique Maingueneau about an enunciative discourse analysis. We divide our intervention into two moments. In the first moment, we present very briefly what would be the five force-ideas developed by Maingueneau throughout its academic course, namely: 1) Global Semantics; 2) Scenes of Enunciation; 3) Constituting Discourses: the literary discourse; 4) The aphorisant enunciation regime 5) Philosophy as a discursive institution. In the second moment, we try to show how

\footnotetext{
${ }^{1}$ Uma versão bastante modificada deste texto foi apresentada em forma de comunicação oral na mesa redonda "O discurso em diferentes perspectivas", durante a IV Jornada Internacional de Estudos do Discurso - JIED, realizada na Universidade Estadual de Maringá - UEM, em 23 de março de 2018. Agradecemos verdadeiramente aos professores Sírio Possenti e Dominique Maingueneau pelas críticas, sugestões e comentários ao nosso texto. Todos os problemas que permaneceram são de nossa inteira responsabilidade. Dedicamos este texto à memória do Prof. Marcelo Dascal, recentemente falecido e com quem aprendemos, pela leitura de seus heurísticos textos, a engatinhar pelos complexos meandros da filosofia da linguística.

${ }^{2}$ Doutor em Linguística e Língua Portuguesa, professor no Departamento de Letras e no Programa de PósGraduação em Linguística da UFSCar e Bolsista em Produtividade e Pesquisa do CNPQ, nível 1 D. E mail: baronas@ufscar.br.

${ }^{3}$ Doutor em Linguística, professor nos Cursos de Comunicação Social - Publicidade e Propaganda e Jornalismo, da UEMG, Unidade de Passos - MG. E-mail sponsoni@yahoo.com
} 
this last idea of force, still in development by Maingueneau can illuminate other researches in the field of the Brazilian discourse, especially in the scope of the Brazilian linguistics. It illustrates this possibility a proposal of discursive work on the writings of the Brazilian linguist Mattoso Câmara Jr.

Keywords: Discourse; Epistemology of discursive studies; Brazilian linguistics. 
Roberto Leiser Baronas; Samuel Ponsoni. Uma análise de discurso de base enunciativa: notas de leitura sobre o percurso epistemológico de Dominique Maingueneau.

\section{Primeiras palavras}

Vamos defender neste artigo a necessidade de se compreender menos procustamente 4 o percurso teórico-metodológico do discursivista francês Dominique Maingueneau acerca de uma análise de discurso de base enunciativa. Em relação a essa hipótese de trabalho, encarecidamente pedimos as vossas indulgências, leitor e leitora, uma vez que os que enunciam aqui são pretensos estudiosos de história e epistemologia do discurso.

Neste sentido, dividimos a nossa exposição neste texto em dois momentos. No primeiro, apresentamos muito rapidamente cinco das muitas ideias-força desenvolvidas por Maingueneau ao longo de seu percurso acadêmico, a saber: 1) Semântica Global; 2) Cenas da Enunciação; 3) Discursos Constituintes: o discurso literário; 4) Enunciação Aforizante e 5) A Filosofia como instituição discursiva. Cumpre asseverar que o percurso epistemológico de Maingueneau não se resume às ideias-força apresentadas aqui. Se assim entendêssemos, estaríamos sorrateiramente desidratando o percurso acadêmico de Maingueneau, que, pelo tempo e pela solidez teórica, é muito mais amplo e complexo. Não é nosso objetivo fazer uma espécie de dicionário com um vocabulário exaustivo acerca dos conceitos perquiridos por Dominique Maingueneau. Trata-se, simplesmente, da reunião de uma espécie de pout-porri, de recorte conceitual que, por um lado, leva, notadamente, em consideração a nossa maior familiaridade com as ideias-força delimitadas e, por outro, por conta mesmo da ruptura epistemológica que tais ideias produzem nos estudos discursivos, não só, mas, especialmente nos da corrente francesa.

No segundo momento, buscamos mostrar como esta última ideia-força, a filosofia como instituição discursiva, ainda em desenvolvimento por Maingueneau, pode iluminar outras pesquisas no campo do discurso brasileiro, sobretudo no âmbito da linguística e da literatura brasílica. Ilustra essa possibilidade uma proposta de trabalho discursivo, ainda bastante embrionária, sobre os escritos do linguista brasileiro Mattoso Câmara Jr. Não nos ateremos a testar as outras hipóteses teóricas perscrutadas por Dominique Maingueneau, aqui suscintamente apresentadas, nos textos de Mattoso Câmara, dado que se trata de uma proposta de Tese, o que fugiria ao escopo de nossa proposta neste artigo.

\footnotetext{
${ }^{4} \mathrm{Na}$ mitologia grega, Procusto era um bandido que vivia em uma floresta e tinha em sua casa uma cama exatamente do seu tamanho. Todos os que passavam pela floresta eram presos e colocados em sua cama. Se a vítima fosse demasiadamente alta ele amputava o excesso de comprimento para ajustá-lo à cama. Se, ao contrário, a vítima fosse de pequena estatura, ela era esticada até atingir o comprimento suficiente de maneira a caber exatamente na cama.
} 
Roberto Leiser Baronas; Samuel Ponsoni. Uma análise de discurso de base enunciativa: notas de leitura sobre o percurso epistemológico de Dominique Maingueneau.

O percurso teórico-metodológico do discursivista francês Dominique Maingueneau acerca de uma análise de discurso de base enunciativa ainda não foi sistematicamente objeto de estudo nem na geografia francesa nem na brasileira. Talvez, isso se deva ao fato de Maingueneau ainda estar em plena atividade de ensino e pesquisa e assim o sendo, também em intensa atividade de (re)formulações teóricas. De qualquer forma, há pelo menos três estudos relevantes que tiveram parcialmente essa preocupação: o trabalho de Sírio Possenti e de Fernanda Mussalim, "Contribuições de Dominique Maingueneau à Análise do Discurso", publicado no livro Da Análise do Discurso no Brasil à Análise do Discurso do Brasil: três épocas histórico-analíticas, organizado por Luciane de Paula e Grenissa Stafuzza; o livro de Sírio Possenti e Roberto Leiser Baronas, Contribuições de Dominique Maingueneau para a Análise do Discurso do Brasil, e o livro em homenagem a Dominique Maingueneau, organizado por Johannes Angermuller e Gilles Philippe, intitulado Analyse du discours et dispositifs d'enunciation: autor des travaux de Dominique Maingueneau, publicado na França, em 2015. Trata-se de um conjunto de reflexões que mostram o quanto o trabalho epistemológico de Dominique Maingueneau é inovador no âmbito dos estudos do discurso.

No entanto, por mais pertinentes e relevantes que sejam (e o são, ressalta-se) nenhum desses trabalhos partiu explicitamente da hipótese de que há no trabalho de Dominique Maingueneau um conjunto muito coerente de ideias-força, alicerçadas numa visada enunciativa, que assevera entre outros princípios a gestão do contexto pelo texto, podendo sustentar teórico-metodologicamente pesquisas em corpora muito distintos daqueles que o próprio Maingueneau frequentou ${ }^{5}$. Vale ressaltar que as ideias-força a serem apresentadas na sequência, embora pareçam receber um tratamento desigual de nossa parte - umas mais descritas do que outras - não são levadas a um tratamento exaustivo. Na verdade, buscou-se mostrar a pertinência e a fecundidade heurística desses conceitos perquiridos por Dominique Maingueneau para a análise dos mais variados tipos de discurso.

\footnotetext{
${ }^{5}$ Por essa perspectiva, cabe ressaltar que, além da proposta que aqui colocamos como a compreensão da obra de Mattoso Câmara a partir dos trabalhos de base em Maingueneau, Sírio Possenti e Maria Cecília Pérez de Souzae-Silva também buscaram em diversos e profícuos momentos estruturar teorias/análises em corpora distintos aos trabalhados pelo próprio pesquisador francês, como, por exemplo, os corpora de discurso humorístico, teses há bastante tempo defendidas por Possenti, e as relações entre linguagem e trabalho perquiridas por Cecília Pérez Souza-e-Silva.
} 


\section{Primeira parte: o percurso epistemológico de Dominique Maingueneau - cinco de suas ideias-força $^{6}$}

\section{Semântica global}

Em Gênese dos Discursos $(2005)^{7}$, uma de suas primeiras obras de natureza mais epistemológicas nos domínios do discurso ${ }^{8}$, Maingueneau, levando em conta análises dos discursos religiosos das doutrinas jansenista e humanista devota, observa que, de um lado, nesses discursos religiosos, há uma semântica global, que rege os múltiplos planos do discurso e, de outro lado, entende que esses planos discursivos devem ser tratados enquanto práticas discursivas, visto que, independentemente dos dispositivos enunciativos e também do sistema semiótico no qual se inscrevem, não estão livres, no sentido de sem regramento, da circunscrição e coerção, de uma ou mais formação(ções) discursiva(s), que manifestam esse regramento desde os gêneros do discurso até as representações de discursos icônicos mobilizados.

O autor francês estabelece uma vigorosa análise, tomando como base os pressupostos da Análise do Discurso, até em suas fases de reformulações e afirmações teóricas na geografia francesa, nos discursos produzidos pelas duas correntes religiosas que, em litígio, polemizaram entre si no contexto francês por mais ou menos 150 anos. A semântica global de Maingueneau propõe-se, então, a investigar diversos gêneros engendrados pelos jansenistas e humanistas, para compreender o embate discursivo entre essas duas correntes religiosas e, mais ainda, observar como os discursos, pelas hipóteses, funcionam como práticas e processos discursivos.

Uma excelente testagem desta ideia-força de Dominique Maingueneau é a Tese de Doutorado da pesquisadora e professora brasileira Fernanda Mussalim, intitulada $A$ transposição erudita da barbárie: aspectos da semântica discursiva do Modernismo no Brasil $^{9}$. A tese de Mussalim de muitas maneiras nos mostra como o discurso dos modernistas

\footnotetext{
${ }^{6}$ Tomamos essa noção de empréstimo do próprio Dominique Maingueneau que em vários de seus trabalhos afirma que o discurso se constitui a partir de algumas ideias-força: o discurso supõe uma organização transfrástica; o discurso é orientado; o discurso é uma forma de ação etc, isto é, trata-se de uma noção que se refere menos a uma teoria particular do que ao entrecruzamento de diversas correntes.

${ }^{7}$ No original Genèses du discours. Bruxelles-Liège: Mardaga, 1984.Tradução brasileira de Sírio Possenti.

${ }^{8}$ Designamos como mais epistemológicas no âmbito do discurso, pois Maingueneau tem também uma vasta produção de obras de natureza mais didáticas, por exemplo, "Initiation aux méthodes de l'analyse du discours", publicado em 1990, pela Hachette Universitaire.

9 Trabalho de tese defendido no Instituto de Estudos da Linguagem - IEL, da Unicamp, sob a orientação de Sírio Possenti, em 2003. Esta tese pode ser acessada na íntegra em: 
Roberto Leiser Baronas; Samuel Ponsoni. Uma análise de discurso de base enunciativa: notas de leitura sobre o percurso epistemológico de Dominique Maingueneau.

brasileiros se formou e se constituiu antes mesmo de 1922, ou seja, ele se constituiu em um processo discursivo, sobretudo entre os anos de 1917 e 1929. Utilizando-se da ideia-força de Semântica Global, o trabalho observa o surgimento do Modernismo no Brasil como prática discursiva atrelada a movimentos e processos de constituição e renovação estéticas mais amplas, visto semanticamente em diversas partes do mundo. Isso mostra que essa prática discursiva levava em conta não somente novas compreensões de arte, o moderno, mas também a relação da arte e o homem naquela conjuntura histórico-política.

Assim, nacionalismo e subjetividade, intimamente ligados ao projeto modernista, são analisados como filtros semânticos, propostos como uma semântica global do discurso modernista, e são também espaços de afirmação e identificação daquilo que era (e deveria ser) um modernismo à moda brasileira, mesmo em relação a outros discursos da mesma época.

\section{Cena de enunciação}

Para Maingueneau, é preciso considerar os discursos em termos de cena da enunciação, evitando, assim, algumas noções, tais como a de "situação de enunciação", que é de ordem estritamente linguística, ou a de "situação de comunicação", que pode ser utilizada numa abordagem puramente sociológica, em que a atividade discursiva é descrita, de algum modo, do exterior, ou ainda como contexto linguístico, que pressupõe uma ordem externa influindo diretamente em uma ordem interna de discursos. Além disso, segundo Maingueneau, o termo "cena" tem a vantagem de poder referir, ao mesmo tempo, a um quadro ("a cena representa...") e a um processo ("ao longo da cena", "uma cena circense" como fez Tiririca em suas campanhas para Deputado Federal pelo Estado de São Paulo nas eleições de 2010 e 2014). Enfim, ela permite realçar a importância do trabalho a que se dedicam permanentemente os participantes de um gênero de discurso: o de colocarem-se em cena.

A análise da cena da enunciação distingue três componentes: a cena englobante, a cena genérica e a cenografia. A cena englobante corresponde ao que comumente se compreende por "tipo de discurso". A cena englobante política, por exemplo, implica uma relação entre um "cidadão", postulante e/ou ocupante de um cargo político, se dirigindo a outros "cidadãos" mostrando como pretende resolver temas de interesse coletivo: saúde,

<http://repositorio.unicamp.br/jspui/bitstream/REPOSIP/269197/1/Silveira_FernandaMussalimGuimaraesLemos _D.pdf> . Acesso em: 02 maio 2019. 
Roberto Leiser Baronas; Samuel Ponsoni. Uma análise de discurso de base enunciativa: notas de leitura sobre o percurso epistemológico de Dominique Maingueneau.

educação, segurança, moradia, transporte público, previdência social etc., caracterização que define o estatuto dos parceiros num certo espaço pragmático, historicamente definido, assim como aqueles discursos devem ser "lidos", isto é, se está diante do discurso de uma propaganda, de uma missiva política, de uma novela literária.

Entretanto, a cena englobante por si mesma não é suficiente para especificar as atividades verbais, visto que os sujeitos falantes não são confrontados diretamente com os campos discursivos, tais como a política, a religião, a publicidade, a literatura etc., ou, ao menos, não se reconhecem diretamente neste campo, não vendo nos discursos produzidos no interior desses campos relações de causa e efeito entre, por exemplo, o discurso e seu interdiscurso, mas sim tem-se sujeitos engendrando gêneros de discurso, que circulam nesses espaços, mais especificamente, com cenas genéricas, que determinam particularmente: suas finalidades, os papéis de seus participantes, um lugar apropriado, certo modo de inscrição na temporalidade (periodicidade, duração, continuidade, prazo de prescrição do texto), suporte (ligado a um modo de transporte e armazenamento, portanto de memorização), eventualmente um plano de texto, certo uso da língua, que no caso do campo da política pode se materializar em um panfleto, um santinho, uma carta de intenções, um programa de governo, etc.

Com efeito, pode-se enunciar um romance, por exemplo, por meio da cenografia de diário íntimo, do relato de viagem, de uma conversa junto à lareira, da troca de cartas de amor, de uma personagem que passa toda a narrativa se perguntando se a sua amada o traiu ou não com o seu melhor amigo, como muito bem o faz Machado de Assis em Dom Casmurro. Essa noção de "cenografia" se apoia na ideia de que o enunciador deve desenvolver, por meio de sua enunciação, a situação a partir da qual ele pretende enunciar, que, por sua vez, é a razão mesma da existência de sua enunciação.

Assim, todo discurso, por sua própria constituição, reivindica a adesão ao seu universo, instituindo a cenografia que o legitima. Evidentemente, tal cenografia é imposta desde o início, mas é por meio da enunciação que essa cenografia imposta pode ser legitimada. A cenografia é, desse modo, ao mesmo tempo, o que engendra o discurso e o que é engendrado por ele; ela legitima um enunciado que, por sua vez, deve legitimá-la, deve estabelecer que essa cenografia de onde vem o discurso é precisamente a cenografia necessária para enunciar como convém neste ou naquele gênero de discurso.

As cenografias geralmente se apoiam em cenas de fala já validadas na cultura, ao que Maingueneau vai nomear de cenas fundantes (1997; 2008): situações de comunicação caracterizadas pelos gêneros, mas também eventos únicos de fala (por exemplo, o slogan de campanha de Barack Obama: "Yes, we can”, nas eleições presidenciais de 2008.). Esse slogan 
Roberto Leiser Baronas; Samuel Ponsoni. Uma análise de discurso de base enunciativa: notas de leitura sobre o percurso epistemológico de Dominique Maingueneau.

de Obama se apoiou no slogan da United Farm Workers já validado na sociedade norteamericana: "Si, se puede". Ou ainda mesmo a (re)utilização desse slogan, reescrito em Yes, we CAM, pela torcida do Clube Atlético Mineiro - CAM - quando da disputa das semifinais e finais da Taça Libertadores da América.

Nesse caso, "validado" não quer dizer "valorizado", mas "já instalado no universo de saber e de valores do público". Em outros termos, esse slogan, desde a sua irrupção, se validou na nossa sociedade como uma espécie de frase-acontecimento que pode ser (re)utilizada em situações nas quais uma grande dificuldade precisa ser transposta.

Nesse sentido, é difícil compreender os eixos do texto e do contexto fora das cenas de enunciação que garantem a sustentação, emergência e as próprias condições de possibilidade de existência de um dado discurso. No mesmo sentido, há algo que envolve a enunciação e não aparece explicitamente no enunciado, mas que de fato é uma dimensão da cenografia dos discursos: é o conceito de ethos.

Não nos referimos ao "ethos retórico", de Aristóteles, de um componente que leva ao convencimento do público pela percepção de traços do caráter do enunciador - virtude, prudência e benevolência ${ }^{10}$-, mas ao ethos descrito por Dominique Maingueneau ${ }^{11}$, que se define, ao mesmo tempo, internamente no discurso e no que seria um pré-discurso, ou representações prévias do locutor que o destinatário possui, conforme os limites postos pelas cenas de enunciação. Como considera Maingueneau:

Além da persuasão pelos argumentos, a noção de ethos permite refletir sobre o processo mais geral da adesão dos sujeitos a determinado posicionamento. Esse processo é particularmente evidente quando se trata de discursos como a publicidade, a filosofia, a política etc., que - diferentemente dos que decorrem de gêneros "funcionais", como os formulários administrativos ou instrucionais devem ganhar um público que está no direito de ignorá-los ou de recusá-los (MAINGUENEAU, 2008, p. 64).

Dessa forma, conforme textualizado na citação, ao estruturar cena enunciativa sobretudo o conceito de cenografia -, consideramos o ethos como um conceito articulador. Articulador entre o dito, o mostrado e o prévio, articulador entre a dimensão cenográfica da

\footnotetext{
${ }^{10}$ De acordo com Maingueneau, a noção de ethos na retórica de Aristóteles “[...] designa ora propriedades associadas ao orador enquanto ele enuncia, ora disposições estáveis atribuídas a indivíduos inseridos em comunidades" (Cf. MAINGUENEAU, 2008, p. 62).

${ }^{11}$ Como definição mais concisa do conceito de ethos para Maingueneau, temos: “- o ethos é uma noção discursiva; ele se constitui por meio do discurso, não é uma 'imagem' do locutor exterior à fala; - o ethos é fundamentalmente um processo interativo de influência sobre o outro; - o ethos é uma noção fundamentalmente híbrida (sociodiscursiva), um comportamento socialmente avaliado, que não pode ser apreendido fora de uma situação de comunicação precisa, ela própria integrada a uma conjuntura sócio-histórica determinada." (Cf. MAINGUENEAU, 2008, p. 63).
} 
Roberto Leiser Baronas; Samuel Ponsoni. Uma análise de discurso de base enunciativa: notas de leitura sobre o percurso epistemológico de Dominique Maingueneau.

enunciação, sendo o ethos como a outra face dessa mesma dimensão enunciativa; articulador de estilos cenográficos, enfim. Então, teríamos o ethos, articulador entre discursos e cultura, observando a presença do ethos em suas cenas de validação histórica, isto é, daquilo que lhe dá sentido discursivo.

Um bom teste desta outra ideia-força de Dominique Maingueneau é o trabalho de Tese da Pesquisadora Brasileira Renata de Oliveira Carreon, intitulado Comunicação política e $(m)$ imagens de si: percursos a caminho do ethos semiotizado ${ }^{12}$.

Este trabalho de pesquisa observa que as diversas mudanças de práticas sociais e discursivas têm seus impactos nos modos de se fazer política, sobretudo nos de fazer campanha eleitoral. O discurso político, por conta das novas tecnologias de comunicação, passa, então, a ser multimodal, ou seja, os atores políticos têm de dar conta do corpo, voz, imagem discursiva, prévias e construídas na enunciação dos discursos, na construção das imagens de si, por conseguinte de um ethos discursivo. Tomando como base a formulação de ethos de Dominique Maingueneau, a pesquisa busca compreender uma dimensão nova do ethos, que seria o ethos semiotizado, que não diz respeito especificamente ao locutor (pai exemplar, professor competente, por exemplo, mas um conjunto de íconotextos que reforçam essa imagem de pai exemplar, professor competente). Trata-se de uma ramificação necessária para se pensar a questão do verbal e não verbal, visando a ampliar o olhar para a multimodalidade discursiva e apresentando metodologia própria para a análise de materiais diversos, ao analisar as campanhas de segundo turno das eleições presidenciais de 2014, respectivamente da ex-presidenta, Dilma Rousseff, e de seu concorrente derrotado, Aécio Neves da Cunha.

\section{Discursos constituintes: o discurso literário}

Com a introdução da noção de discursos constituintes que seriam, entre eles, o discurso literário, o discurso filosófico, o discurso científico e o discurso religioso, Maingueneau busca e faz, analítica e teoricamente, com que essas mesmas categorias epistemológicas mudem sua operacionalidade, adaptando-se à apreensão de um discurso que, ao mesmo tempo, é autoconstituinte, ou seja, discursos constituintes que ao se lançar à enunciação já predispõem de autorização, uma forma de exercer um poder em seus

\footnotetext{
${ }^{12}$ Trabalho de pesquisa defendido no Programa de Pós-Graduação em Linguística, da UFSCar, sob a orientação de Roberto Leiser Baronas, em 2018. Disponível em: <https://repositorio.ufscar.br/handle/ufscar/9956?show=full>. Acesso em: 2 maio 2019.
} 
Roberto Leiser Baronas; Samuel Ponsoni. Uma análise de discurso de base enunciativa: notas de leitura sobre o percurso epistemológico de Dominique Maingueneau.

respectivos campos, no sentido de constituir a legitimidade de todos os discursos que ali circulam, e a um modo de operação na memória e no interdiscurso específicos, e heteroconstituinte, isto é, estes mesmos discursos constituem, em inúmeros casos, a validação e composição de outros discursos, haja vista que outros tipos de discurso buscam nos discursos constituintes sua legitimação.

Um breve exemplo da pertinência teórica da tese de Dominique Maingueneau sobre os discursos constituintes é o que acontece com muita frequência no campo da comunicação. Toda vez que uma discussão precisa ser aprofundada, independentemente do campo do conhecimento (economia, educação, saúde, segurança, etc.), os jornalistas convidam um especialista da área para debater tal questão. O contrário não acontece.

Posicionar o estudo literário dentro dos domínios discursivos é fazer um duplo movimento de construção teórica e metodológica: primeiramente, é trazer aos estudos discursivos, digamos, os corpora menos privilegiado desde as bases de fundação da Análise do Discurso francesa, que se pressupõe, inicialmente, principalmente entre o final dos anos 1960 e meados dos 1970, como uma disciplina interpretativa de discursos políticos; em segundo, é trazer o discurso, como ciência autônoma propriamente dita, ao âmago das problematizações dos estudos literários. Não como uma linha acessória aos estudos literários, ou uma caixa de ferramentas sempre disposta a se adequar ao discurso literário, mas sim se afirmando teoricamente diante dos estudos literários, que se dividiam até meados do século $\mathrm{XX}$, grosso modo, entre estudos históricos, sociológicos ou psicobiográficos, ou seja, importava aos estudos literários, respectivamente, o conhecimento histórico dos textos ditos prestigiosos, a literatura de clássicos e cânones, as correspondências entre um chamado "contexto" histórico e a obra produzida, e os elementos perceptivos e/ou implícitos dos traços psicológicos e biográficos do autor nos textos literários que ele produziu.

Nesse sentido, o discurso literário vem para as lentes do discurso e isso significa sair do esquema imposto pelos movimentos românticos do final do século XX, sobretudo, cujo direcionamento recobria "direta" ou "indiretamente" uma visão de mundo da instância criadora, quase exclusivamente.

Para Maingueneau, a enunciação literária, assim como todas as enunciações, não escapa ao lugar e ao momento em que surgiu e a quem se dirige. Assim como não escapa a esse engendramento, portanto, o discurso literário não figuraria mais como "o" discurso acima dos demais discursos socialmente sustentados, mas um dos discursos que tem seus alicerces fincados em terreno social. Dito de outro modo, há de se entender que a palavra do escritor - 
Roberto Leiser Baronas; Samuel Ponsoni. Uma análise de discurso de base enunciativa: notas de leitura sobre o percurso epistemológico de Dominique Maingueneau.

em um sentido amplo, quase metafórico - é sempre regulada, seja em termos de norma, de instituição, de, para e a quem se destina.

Sendo assim, num discurso literário não há separação entre dois planos, texto e conjuntura histórica. A transcendência da obra, bem como a ideia de que nisso há um conteúdo a ser transmitido, não pode ser afastada de suas condições de enunciação. A estrutura social, e seu real de uma história materialista, não é única e exclusivamente a obra em si nem o exterior da obra, uma imagem de si refletida, seja pelo lado textual, seja pelo lado histórico, tal como Narciso diante do lago; a sua voz é sim colocada e regulada pelo próprio texto no tracejar de sua enunciação e a gestão que ele, discursivamente, faz das estruturas e conjunturas históricas, desde as primeiras garatujas até as palavras mais firmes e sóbrias no que se tem como obra ou processo de dizer "acabado".

Com efeito, concebendo o "texto" à luz de um ethos discursivo, por exemplo, podemos conceber o enunciador também por meio das dimensões próprias da autoria. $\mathrm{O}$ autor não se reduz a uma posição, ou àquele que exerce a função enunciativa do/no texto em certo momento. No processo de subjetivação das formas do discurso, tem-se comumente a impressão de que a "função autor" se divide entre um "sujeito empírico" e um "nome". Porém, para Maingueneau não é suficiente pautar a análise do funcionamento da autoria sobre a dualidade "escritor e enunciador", ou seja, por um princípio "que distingue um 'escritor', um ser de carne e osso dotado de um estado civil, e um 'enunciador', correlato de um texto"13.

Nesse sentido, cabe abordar a autoria de maneira mais ampla, centrando-se sobre três instâncias distintas e não duas que separam formalmente um "sujeito biográfico" de um "sujeito enunciador". Essas instâncias, Maingueneau as define como a pessoa, o escritor e o inscritor:

A denominação "a pessoa" refere-se ao indivíduo dotado de um estado civil, de uma vida privada. "O escritor" designa o ator que define uma trajetória na instituição literária. Quanto ao neologismo "inscritor", ele subsume ao mesmo tempo as formas de subjetividade enunciativa da cena de fala implicada pelo texto [...] e a cena imposta pelo gênero do discurso: romancista, dramaturgo, contista... O "inscritor" é, com efeito, tanto enunciador de um texto específico como, queira ou não, o ministro da instituição literária, que confere sentido aos contratos implicados pelas cenas genéricas e que delas se faz o garante. ${ }^{14}$

\footnotetext{
${ }^{13}$ Cf. Dominique Maingueneu. Discurso Literário. Tradução de Adail Sobral. São Paulo: Contexto, 2006, p. 134.

${ }^{14}$ Cf. Idem, Ibid. p. 136.
} 
Roberto Leiser Baronas; Samuel Ponsoni. Uma análise de discurso de base enunciativa: notas de leitura sobre o percurso epistemológico de Dominique Maingueneau.

Ou seja, é possível estudar o funcionamento da autoria a partir do que está no texto como aquilo que reflete o autor: pelos atributos sociais e individuais de um sujeito biográfico, a pessoa; pela sua inserção em uma determinada cena englobante, um meio literário, o científico, o escritor; e também por meio de uma função estética e/ou didática, o texto em sua cenografia, o inscritor. Mas o autor não é somente a fonte de enunciação dos seus textos, e sim um dos meios pelos quais eles tomam significado. Ao mesmo tempo em que escreve seus textos, o autor, numa dada conjuntura, não tem autonomia da gestão de sua obra. Portanto, deve-se considerar a instituição em que se inscreve a obra de um autor e suas regras próprias, em função do contexto sócio-histórico de produção dos textos.

Por meio da articulação das três instâncias da autoria, mobilizadas isoladamente ou em conjunto por quem organiza a obra de um autor, faz-se importante a compreensão dos meios pelos quais se dá a criação de uma imagem de autor. A construção dessa imagem escapa à esfera pura e simples da elaboração ou escritura do texto e ultrapassa o que seria a dimensão da "figuração" do autor - como ele se porta no campo do discurso e na cena genérica em que se inscreve: se dá entrevistas, se frequenta círculos políticos, se participa de centros de pesquisa, se assina manifestos, se lidera grupos sociais, se publica blogs na internet ou se se mantém isolado do público, se funda e/ou preside sociedades científicas, se edita e/ou cria periódicos científicos na área, etc. Além dessa dimensão em que figura a imagem do autor, existem procedimentos de regulação dos textos que são responsáveis por reescrever determinada obra na medida em que se criam imagens distintas de um mesmo autor. De acordo com Maingueneau:

De modo geral, um manifesto ou um prefácio têm como função principal pôr as obras em conformidade com as normas, seja para mostrar que se seguem as normas existentes ou para propor soberanamente as do autor. Essa função de "regulação" também tem relação com colocar em perspectiva um texto, seu perfil com referência ao que poderíamos chamar de a Opus, isto é, a trajetória de conjunto em que cada obra singular assume um lugar. ${ }^{15}$

A dimensão da regulação constitui-se, portanto, na negociação da imagem do autor, que implica a restrição, a aprovação ou o incentivo a um tipo de circulação, bem como a escolha de prefaciadores e de comentadores diversos para a inserção de sua obra em determinados campos do discurso conforme for conveniente. Em síntese, cria-se uma maneira diferente de ler os textos de um autor por meio de sua imagem. A título de ilustração, Maingueneau nos mostra que é possível ver como gêneros "privados" do discurso, como

${ }^{15}$ Cf. Idem, Ibid. p. 143. 
Roberto Leiser Baronas; Samuel Ponsoni. Uma análise de discurso de base enunciativa: notas de leitura sobre o percurso epistemológico de Dominique Maingueneau.

correspondências do sujeito biográfico, da pessoa, passam ao domínio "público" do autor, enquanto escritor e/ou inscritor, pela gestão de sua obra. Surgem assim novos livros, textos inéditos, cartas etc. que são publicados, constituindo uma forma de gerir o contexto da imagem do autor. E, no processo de construção da imagem do autor, vemos momentos de releituras, de reedições, ou seja, a produção de novas imagens ${ }^{16}$ ou recrudescimento de imagens já criadas.

Um ótimo teste desta outra ideia-força de Dominique Maingueneau é o trabalho de Tese da Pesquisadora Brasileira Kelen Cristina Manzan Rodrigues, intitulado Por uma análise do discurso literário: funcionamento da autoria em Oscar Wilde e construção de imagens de autor ${ }^{17}$. Resumidamente, o trabalho de Rodrigues mostra o funcionamento da autoria por meio da construção de imagens discursivas de autor, a partir dos trabalhos e imagem do escritor Oscar Wilde. A pesquisadora analisa e interpreta em sua tese como prefaciadores e críticos ingleses e franceses do autor Wilde se valeram de diversos recursos discursivos, entre eles as faces da autoria: inscritor, pessoa, escritor, para construir imagens de autor para Oscar Wilde social e literariamente validadas.

\footnotetext{
${ }^{16}$ A título de exemplo citamos a descoberta, em 2015, de um poema inédito de Machado de Assis por parte do pesquisador do Departamento de Letras da UFSCar, Wilton Marques. O poema inédito "O grito Ipiranga" foi publicado no jornal Correio Mercantil, em 07 de setembro de 1856, mas não havia sido coligido pelos estudiosos de Machado de Assis. A descoberta desse poema com um conteúdo bastante ufanista, de louvação ao Brasil, em um jornal carioca que à época gozava de bastante prestígio, ajuda na construção de uma imagem distinta do autor Machado de Assis, que até então predominava na sua fortuna crítica. Essa nova imagem afeta as três dimensões da autoria (pessoa, escritor e inscritor), proposta por Maingueneau, conforme a atesta a asserção do pesquisador Wilton Marques acerca de sua descoberta: “O texto não chama atenção pela qualidade literária, mas por mostrar um Machado adolescente e em fase de amadurecimento intelectual. Os 76 versos são uma forma de homenagem ao dia da independência, uma forma nacionalista que o escritor logo abandonou. A nova descoberta, ao invés de trazer explicações, levanta ainda mais dúvidas sobre uma época pouco conhecida: a adolescência de Machado de Assis. A grande questão para os machadianos é que não se sabe bem como um jovem intelectual negro, em uma sociedade escravocrata como a brasileira, conseguiu se inserir na intelectualidade brasileira". A entrevista do pesquisador pode ser conferida na íntegra no endereço: http://g1.globo.com/sp/sao-carlosregiao/noticia/2015/03/professor-da-ufscar-encontra-poema-esquecido-do-autor-machado-de-assis.html. Ou também a Campanha Machado de Assis Real, idealizada pela Faculdade Zumbi dos Palmares (http://www.zumbidospalmares.edu.br/campanha-machado-de-assis-real/) e divulgada na internet para mostrar que Machado de Assis era negro e não branco como divulgado, sobretudo, nos livros de literatura e de história. Trata-se de um abaixo assinado cuja ideia da campanha "Machado de Assis Real", "surgiu de uma inquietação com a questão do embranquecimento, que era muito comum na época, pois em um contexto social de preconceito racial, a figura de poder e respeito não poderia ser representada por negros. Machado de Assis era negro e muita gente não sabe disso. A campanha \#MachadodeAssisReal vai reparar essa injustiça. Assine o abaixo-assinado para que as editoras e livrarias deixem de imprimir, publicar e comercializar livros em que o escritor aparece embranquecido e substitua a imagem preconceituosa pela foto de Machado de Assis real. Link do site oficial: http://machadodeassisreal.com.br/"

${ }^{17}$ Trabalho de tese defendido no Programa de Pós-Graduação em Estudos Linguísticos da Universidade Federal de Uberlândia, em 2014, sob a orientação de Fernanda Mussalim. Disponível na íntegra em: <https://repositorio.ufu.br/handle/123456789/15299>. Acesso em: 2 maio 2019.
} 
Roberto Leiser Baronas; Samuel Ponsoni. Uma análise de discurso de base enunciativa: notas de leitura sobre o percurso epistemológico de Dominique Maingueneau.

\section{A enunciação aforizante}

Dominique Maingueneau perscruta mais uma boa hipótese teórica ${ }^{18}$ para explicar o destacamento, a circulação e a transformação de pequenas frases tanto na nossa sociedade contemporânea quanto nas antigas. Em suas convicções pesquisa ${ }^{19}$ sobre a pequena frase, ele procura mostrar, por um lado, como certos textos circulam: se inteiros, em fragmentos, adaptados, em edições originais, transformados, traduzidos. E, por outro lado: por que, de um texto integral, frequentemente circulam apenas excertos: estrofes, versos, finais, começos, pontos culminantes. Nesse sentido, Maingueneau defende que as pequenas frases devem ser interpretadas a partir do seu destacamento em dois grupos: as destacadas por natureza, como as do Barão de Itararé, que pela sua própria configuração linguística - estrutura, rimas favorece a circulação em diferentes textos, e as destacadas de um texto como "Não vamos desistir do Brasil", mesmo sem ter uma configuração linguística suscetível ao destacamento, mas com bastante pregnância.

Para Maingueneau, ainda, frases semelhantes às elencadas, por não se deixarem aprisionar em um único texto e, também por sua aspiração a ser universalmente conhecidas e aceitas pelo conjunto dos falantes de uma língua, de maneira a serem utilizadas em circunstâncias distintas, inscrevem-se num modo de funcionamento diverso daquele dos textos de uma maneira em geral. Esse funcionamento discursivo é denominado pelo pesquisador de enunciação aforizante.

O autor defende que a ideia central da problemática da aforização é a de que as "frases sem texto" não precisam de textos e de gêneros para circular ou que as primeiras sejam completamente independentes dos segundos. Para o teórico francês, o essencial é que a enunciação aforizante tem um modo de funcionamento enunciativo próprio, que difere da ordem textualizante, na qual estão inscritos os textos e os gêneros e que essas diferentes ordens estão em constante tensão, que pode ser mais ou menos forte.

Com efeito, entre um enunciado aforizado - "uma frase sem texto" - e um texto não há diferença de dimensão, mas de natureza. Nesse sentido, a enunciação corresponde a dois regimes distintos - aforizante, ligada aos destacamentos, e textualizante, ligada aos gêneros que dizem respeito a duas diferentes formas de considerar a comunicação verbal e o sujeito da

\footnotetext{
${ }^{18}$ Les phrases sens texte. Armand Colin. Paris, 2012. Tradução brasileira: Frases sem texto. São Paulo: Parábola, 2014. Tradutores: Sírio Possenti et al.

${ }^{19}$ Em palestra realizada durante o VIII Seminário Cenas da Enunciação, em maio último, na Universidade Federal de Mato Grosso, Dominique Maingueneau, ao discorrer sobre o seu percurso acadêmico, designou suas hipóteses de trabalho como convicções acerca do discurso.
} 
Roberto Leiser Baronas; Samuel Ponsoni. Uma análise de discurso de base enunciativa: notas de leitura sobre o percurso epistemológico de Dominique Maingueneau.

fala. Desse modo, enquanto a enunciação textualizante define duas posições correlativas de produtor e de receptor, dois papéis de interação, a enunciação aforizante, ao contrário, institui uma cena de fala em que não há interação entre dois protagonistas colocados no mesmo plano: é o próprio indivíduo que se exprime aquém/além de todo papel. Conforme assevera Maingueneau, embora a aforização centre a enunciação no locutor, não se trata de um papel de locutor como na enunciação textualizante, um ponto de vista discursivo, mas de um sujeito que fala do alto, que é autorizado a enunciar a sua verdade, prescindindo da negociação, exprimindo uma convicção, uma experiência, uma palavra de ordem.

Com o exemplo do Barão de Itararé, quando este personagem da cultura brasileira subverte um provérbio como "Quem ama o feio, bonito lhe parece", transformando-o em "Quem ama o feio é porque o bonito não aparece", além de transformar o provérbio original em pastiche, apresenta-se numa instância enunciativa de quem fala do alto, de alguém que se coloca em contato com uma Fonte Transcendente, enunciando uma verdade que pretende inquestionável.

Em suma, o que se deve levar em conta nessa problemática é somente a pretensão vinculada à aforização, a de ser uma palavra absoluta, sem contexto, convocada em um texto que, por natureza não é absoluto. O essencial é, então, a tensão mais ou menos forte que se estabelece entre a aforização e o todo textual que a acolhe.

Um ótimo teste desta outra ideia-força de Dominique Maingueneau é o trabalho de Tese da Pesquisadora Brasileira Ana Raquel Motta de Souza, intitulado Heterogeneidade e Aforização: uma análise do discurso dos Racionais $M C s .{ }^{20}$ De maneira geral, esse trabalho de tese busca compreender como frases dadas a circular como provérbios, máximas, citações bíblicas, expressões fixas, entre outros predominam nos discursos produzidos pelo grupo de Rap nacional, Racionais MCs. Em suma, assevera-se que a enunciação aforizante são partes constitutivas das canções do citado grupo de rap e que esse funcionamento enunciativo produz um efeito de enunciação coletivizada e de fortalecimento da comunidade discursiva, que incorpora e reproduz os enunciados do grupo.

\footnotetext{
${ }^{20}$ Trabalho de tese defendido no Instituto de Estudos da Linguagem - IEL, da Unicamp, sob a orientação de Sírio Possenti, em 2009. Esta tese pode ser acessada na íntegra em: <http://repositorio.unicamp.br/jspui/handle/REPOSIP/268877>. Acesso em: 2 maio 2019.
} 
Roberto Leiser Baronas; Samuel Ponsoni. Uma análise de discurso de base enunciativa: notas de leitura sobre o percurso epistemológico de Dominique Maingueneau.

\section{A filosofia como instituição discursiva}

Dominique Maingueneau em seu livro La philosophie comme instituition discursive, publicado em 2015 pela Editora Labert-Lucas, de Paris, toma como corpus discursivo de estudos textos da filosofia europeia moderna. Para o autor,

[...] [n]a instituição discursiva se misturam, inextricavelmente, a instituição como ação de estabelecer, processo legítimo de construção, e instituição, no senso comum, de aparelhos que organizam as práticas. O que importa aqui, é que a reversibilidade entre a atividade enunciativa e as estruturas que são tanto a condição e o produto. Se trata, assim, de colocar em evidência uma atividade enunciativa que deve gerenciar sua presença no mundo que ela constrói e no mundo onde ela se constrói, que se desdobra como dispositivo de legitimação da situação de enunciação de onde ela pretende se manifestar. Portanto, não procuramos, como na abordagem estruturalista, uma teoria da "articulação" entre o texto e uma realidade extra-verbal muda: isso seria pressupor o compartilhamento mesmo que procuramos superar (MAINGUENEAU, 2015, p. 14). ${ }^{21}$

Maingueneau compreende a instituição discursiva com base numa perspectiva em que não há uma separação radical entre texto e contexto, mas que o primeiro é quem faz a gestão do segundo; assim, é possível refletir sobre o valor duplo da "instituição": processo de instauração reconhecida e conjunto de aparelhos e de regras estabelecidas.

Nesse sentido, por meio do movimento da instituição discursiva, articulam-se as instituições que dão sentido à enunciação singular (a estrutura do campo, o estatuto da linguística, os gêneros do texto...) e o movimento pelo qual se institui o discurso, instaurando progressivamente certo mundo no enunciado e legitimando a cena de enunciação e o posicionamento no campo que torna tal enunciado possível. No entendimento desse pesquisador,

[...] cada gesto criador mobiliza, queiramos ou não, o espaço que o torna possível, e tal espaço apenas existe por meio dos gestos criadores que os tornam possíveis. A obra, por meio do mundo que ela configura através do estabelecimento do texto, reflete legitimando as condições de sua própria atividade enunciativa. $\mathrm{O}$ papel crucial que deve praticar a "cena da enunciação", que não é restringível nem ao texto, nem à situação de comunicação que poderíamos descrever do exterior. A obra é enunciada através de uma situação que não é um quadro pré-estabelecido e fixo: ela pressupõe uma cena de fala determinada que deve validá-la por meio do próprio enunciado. A instituição discursiva é, assim, o movimento pelo qual se passa de um a outro, para que a obra e as suas condições de enunciação se apoiem mutuamente (MAINGUENEAU, 2015, p. 15) ${ }^{22}$.

\footnotetext{
${ }^{21}$ Tradução nossa do original.

${ }^{22}$ Tradução nossa do original.
} 
Roberto Leiser Baronas; Samuel Ponsoni. Uma análise de discurso de base enunciativa: notas de leitura sobre o percurso epistemológico de Dominique Maingueneau.

\section{Segunda parte: a linguística brasileira como instituição discursiva}

Na segunda parte deste estudo, temos como objetivo precípuo refletir sobre a produção regular de trabalho dos linguistas brasileiros, isto é, acerca do seu trabalho de escritura linguística, que excede à textualidade. Mais, especificamente, nos debruçaremos sobre os escritos de Joaquim Mattoso Câmara Jr, considerado, pela maioria dos linguistas brasileiros, o iniciador da linguística de língua portuguesa. Nossa hipótese central de trabalho é a de que Mattoso Câmara, a partir de seu livro Princípios de Linguística Geral, cuja primeira edição é de 1941, institui, por um lado, a linguística brasileira como um espaço de produção, e não apenas de reprodução de saberes linguísticos, determinado por certas regras e modelos de cientificidade e, por outro, se posiciona no campo de estudos da linguagem, até então tomado no caso brasileiro pelas abordagens gramatical e filológica e estrangeiro pelo modelo estruturalista.

A pesquisa linguística no Brasil, se comparada com a de outros países como França, Alemanha e Estados Unidos, começou bem mais tardiamente. Se nessas últimas geografias acadêmicas, sobretudo nas duas primeiras, a linguística emerge com força epistemológica no início dos anos 20 do século passado, no caso brasileiro, ela irá emergir somente no início dos anos $1940^{23}$.

Essa “decalagem" em relação a outros contextos se deveu basicamente à predominância de então dos estudos de natureza gramatical e filológica, esta última entendida como crítica de textos. Gramática e Filologia eram os grandes inimigos com os quais a nascente Linguística de então teve de disputar espaço. Sobre a mudança de paradigma nos estudos da linguagem, engendrada por Mattoso Câmara, nos diz Carlos Falcão Uchôa, um dos principais organizadores e curadores da obra de Mattoso:

Representa um consenso no mundo acadêmico brasileiro ser a obra de Mattoso Câmara sobre a língua portuguesa, na perspectiva sincrônica, um marco, um patamar, na história do estudo e do ensino da nossa língua, pela nítida mudança de

\footnotetext{
${ }^{23}$ A pesquisadora brasileira Cristina Altman, em seu texto "Retrospectivas e perspectivas da historiografia da linguística no Brasil”, publicado na Revista Argentina de Historiografia Linguística, em 2009, com base em um corpus de descrição gramatical de línguas americanas, produzido entre os séculos XVI e XIX pelos missionários europeus, a partir de um modelo latino de referência, questiona o fato de que a história da linguística teria efetivamente no caso brasileiro começado com Joaquim Mattoso Câmara. No entendimento dessa autora, as descrições gramaticais dos religiosos europeus deveriam ser também o objeto de uma investigação sobre a história da linguística no Brasil. Entendemos que as postulações de Altman apesar de muito pertinentes para o campo da historiografia linguística, não o são para o projeto de pesquisa em questão, dado que este não tem um cunho historiográfico e sim discursivo.
} 
Roberto Leiser Baronas; Samuel Ponsoni. Uma análise de discurso de base enunciativa: notas de leitura sobre o percurso epistemológico de Dominique Maingueneau.

paradigma por ele adotada, um referencial teórico novo, então, entre nós, o estruturalismo, que contrastava de todo com o discurso metalinguístico então dominante no Brasil, identificado como discurso filológico, centrado, sobretudo, na história da língua e na documentação da língua literária clássica (UCHÔA, 2004a, p. 1).

Mattoso Câmara Jr., com a publicação de seu livro Princípios de Linguística Geral é, inaugura uma reflexão teórica sobre a linguagem no Brasil. Até então, os estudos gramaticais e filológicos desenvolvidos por Said Ali, Antenor Nascentes, Souza da Silveira e outros, além e aquém de não terem um caráter mais teórico, não eram aplicáveis a línguas distintas do português. Nesse sentido,

[...] pode-se dizer que a Linguística Teórica passa a ser reconhecida como disciplina acadêmica, entre nós, a partir dos Princípios de Linguística Geral de Mattoso Câmara Jr. e a partir de quando ele assume, em 1948, a docência dela, na Faculdade Nacional de Filosofia da Universidade do Brasil, docência que iria exercer até pouco antes de falecer, em 1970. Na verdade foi o primeiro professor a lecionar Linguística regularmente num Curso de Letras do país... (UCHÔA, 2005, p. 70).

Conforme já indicado por Uchôa (2005), o livro Princípios de Linguística Geral: como introdução aos estudos superiores da Língua Portuguesa, de Joaquim Mattoso Câmara Jr., publicado pela Padrão Livraria Editora, embora temerária esta asserção, se constitui numa espécie de certidão de nascimento da linguística brasileira. Esse livro está dividido em 19 capítulos, que percorrem desde o objeto de estudo da Linguística até a classificação das línguas. Desde a sua primeira edição, de 1941, já foi reeditado e revisto sete vezes. A primeira edição conta com um prefácio de Sousa da Silveira. Nesse prefácio, Silveira afirma:

[...] as lições de Linguística do Dr. Mattoso Câmara não deviam limitar-se ao campo restrito da Universidade e sim estender-se também fora dela, em benefício de tantos estudiosos de idiomas, professores ou alunos, que de certo gostariam de dar um pouco de sistematização aos seus conhecimentos e abarcar, do alto e numa síntese salutar, o mecanismo geral da linguagem articulada (SILVEIRA, 1941, p. $5)$.

Para além de uma síntese das teorias linguísticas vigentes à época, Princípios se configura como um programa de investigação científica que busca compreender a linguagem não somente nos seus aspectos sistêmicos, como propõe Saussure no Curso de Linguística Geral(CLG), de 1916, mas principalmente na sua relação com a cultura e com o estilo individual dos falantes, como se pode ver na figura a seguir: 
Roberto Leiser Baronas; Samuel Ponsoni. Uma análise de discurso de base enunciativa: notas de leitura sobre o percurso epistemológico de Dominique Maingueneau.

Imagem 1 - Fragmento ícono-textual retirado do livro Princípios de Linguística Geral, de Joaquim Mattoso Câmara, 1941, p. 21

Assim, a língua é uma parte da cultura, mas se destaca do todo e com ele se conjuga dicotomicamente:
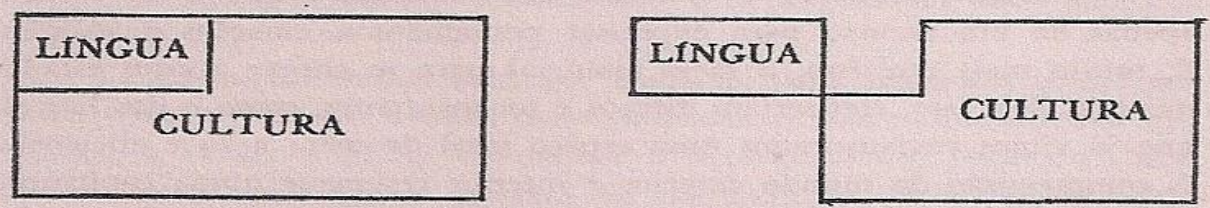

Acresce, em segundo lugar, que só existe para este fim e não tem finalidade em si mesma. A sua função é expressar a cultura para permitir a comunicação social.

Para o pesquisador brasileiro, a linguística propriamente dita, ou o estudo da Língua na acepção saussuriana, não abrange o fenômeno linguístico em sua totalidade. Ficam de lado as intenções de manifestação psíquica e apelo, que os discursos individuais, em regra, carreiam em si e correspondem à expressão.

Desse modo, para Mattoso, cada ato de linguagem ou discurso se fundamenta num sistema de representação linguística, que é a língua, e também sistematiza os recursos linguísticos representativos para a manifestação psíquica e o apelo numa estruturação estética, que é o estilo. A língua é, primariamente coletiva, mas pode ter secundariamente peculiaridades individuais, constituindo o idioleto. $\mathrm{O}$ estilo parte primariamente de um impulso pessoal, mas há todo um conjunto de coincidências estilísticas na comunidade linguística, constituindo-se o estilo coletivo. Aspectos que podem ser verificados na figura a seguir:

Imagem 2 - Fragmento ícono-textual retirado do livro Princípios de Linguística Geral, de Joaquim Mattoso Câmara, 1941, p. 29

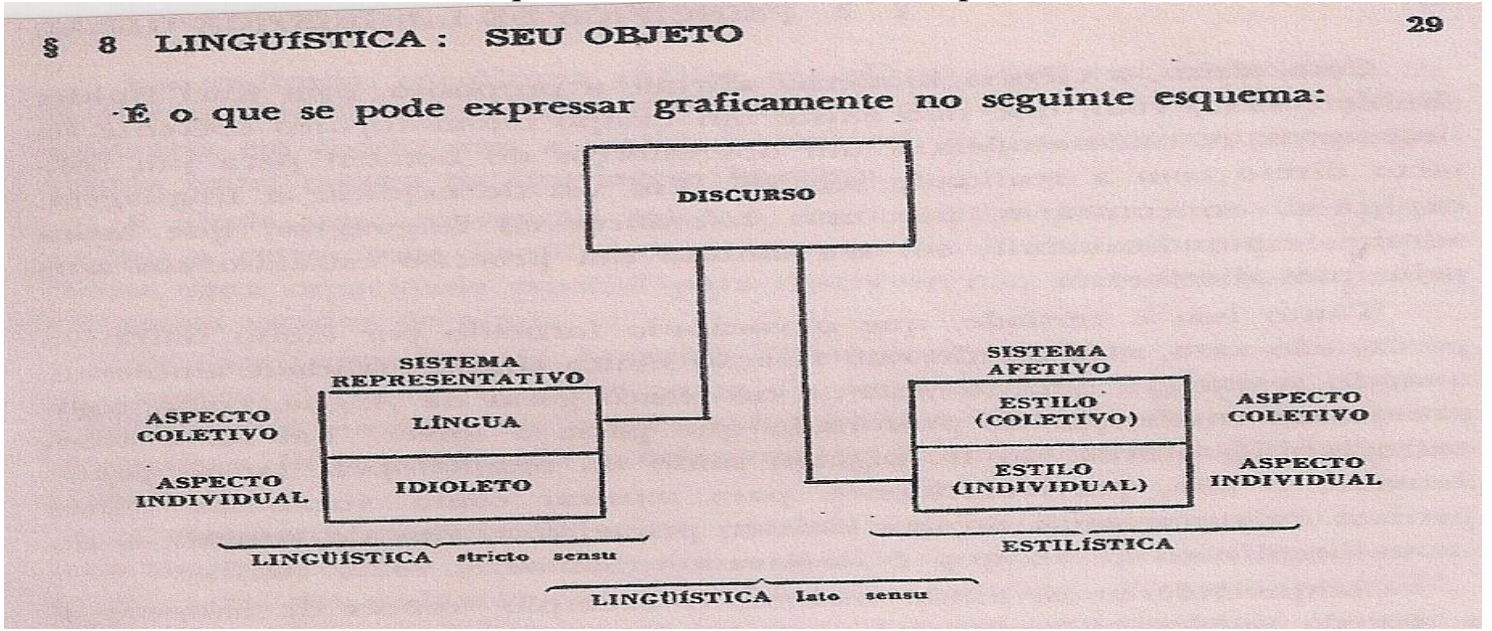


Roberto Leiser Baronas; Samuel Ponsoni. Uma análise de discurso de base enunciativa: notas de leitura sobre o percurso epistemológico de Dominique Maingueneau.

No entendimento de Mattoso Câmara Jr. a linguagem humana se distingue da linguagem animal, porque é constituída de segmentos articulados entre si e com uma significação permanente. O seu objetivo essencial é a representação, isto é, uma estruturação da experiência, a qual torna compreensível e comunicável, mas há os objetivos correlatos de manifestar estados de alma, sem intento imediato de comunicação, e de empolgar emocionalmente o próximo. Ela é vocal, fundamentada em sons produzidos por um conjunto de órgãos que constituem o aparelho fonador. Não é, entretanto, inerente somente ao organismo humano, mas ao contrário um fato de cultura, concretizando-se em sistemas "arbitrários" de comunicação vocal, ou línguas, que cabe à linguística estudar em seus princípios organizadores.

Em relação à cultura integral de uma comunidade humana, a língua é uma de suas manifestações, mas ela se destaca como microcosmos cultural, que a engloba e a comunica. Assim, a linguística se aproxima e se distingue, ao mesmo tempo, da antropologia cultural ou etnologia, e da psicologia; e as relações, entre elas existentes, condicionam disciplinas intermediárias - a etnolinguística e a psicolinguística. A linguística parte do aspecto, a rigor coletivo da língua, divide-se em linguística stricto sensu e estilística, o que corresponde à língua, como sistema representativo, e ao estilo, como processo de exteriorização psíquica e apelo.

Essa rápida incursão ${ }^{24}$ por algumas passagens capitais do livro Princípios de Linguística Geral nos mostra que a recepção do programa de pesquisa saussuriana no Brasil (CLG) se dá com Mattoso Câmara numa espécie de cadinho epistemológico em que o linguista brasileiro funde as ideias do próprio F. de Saussure com as ideias de Sapir e de Bally.

Trata-se de uma tentativa de trazer novamente à tona questões que foram deixadas de lado por Saussure no CLG, tais como o caráter cultural da língua e o aspecto estilístico dos falantes. Aspectos relativos à subjetividade, sobretudo, que só bem mais tarde, meados dos anos cinquenta do século XX, foram sistematizados por Émile Benveniste, no contexto europeu.

Se no contexto francês, como nos mostra Puech (2005), o CLG, editado por Bally, Sechéhaye e Riedlinger, é recebido inicialmente com repulsa, dado que se trataria de uma

\footnotetext{
${ }^{24}$ Uma versão bastante aprofundada de ditos e escritos de/sobre Mattoso Câmara Jr. também foi objeto de comunicação individual, intitulada "Uma leitura discursiva de ditos e escritos de/sobre Mattoso Câmara Jr.", apresentada no 66 Seminário do Grupo de Estudos Linguísticos do Estado de São Paulo - GEL, realizado na cidade de São José do Rio Preto, no período de 10 a 13 de julho de 2018. O resumo desta comunicação pode ser acessado em: <https://www.letraria.net/wp-content/uploads/2018/07/Caderno-de-resumos-do-66\%C2\%BASemin\%C3\%A1rio-do-GEL-letraria.pdf >.
} 
Roberto Leiser Baronas; Samuel Ponsoni. Uma análise de discurso de base enunciativa: notas de leitura sobre o percurso epistemológico de Dominique Maingueneau.

perversão do verdadeiro Saussure, que estaria presente somente no ELG, no contexto brasileiro, em Princípios de Linguística Geral, diferentemente, o pensamento saussuriano do CLG é recebido como uma teoria que, embora bem fundamentada cientificamente, carece de ajustes, sobretudo, no tocante às relações entre língua e cultura, e língua e estilo dos falantes. Essa "recepção" brasileira implica a construção de um programa de pesquisa totalmente singular, bastante diferente dos programas norte-americano e europeu.

Com efeito, tem-se nos trabalhos posteriores de Mattoso Câmara, especialmente, os que tomam como objeto a língua oral, a estilística e as línguas indígenas, bons exemplos da continuação do programa de pesquisa iniciado por Mattoso Câmara em seu Princípios de Linguística Geral.

\section{Palavras semifinais}

A sucinta análise empreendida do livro inaugural da linguística brasileira nos mostra que a linguística em solo brasílico, já no seu nascedouro, se constitui, por um lado, como um espaço de produção de conhecimentos e não apenas de reprodução e, por outro, como um posicionamento divergente no campo de estudos da linguagem de então.

Com efeito, como dar conta dessa linguística, que institui novos conhecimentos a partir de determinadas regras, modelos de cientificidade, portanto como uma instituição discursiva? Obviamente, é preciso ir muito mais além do que aqui apresentamos para pensar de maneira mais consistente a linguística brasileira como uma instituição discursiva.

Assim, para dar conta de pensar a linguística, a partir dos escritos de/sobre Mattoso Câmara, como uma instituição discursiva, é necessário produzir um triplo deslocamento em relação aos trabalhos que se debruçaram até o presente momento em relação à história e à filosofia da linguística produzida no Brasil:

a) É preciso relacionar os textos de/sobre Mattoso Câmara aos quadros que excedem a textualidade: a cena de enunciação, o campo da linguística, éthos, as diferentes dimensões da autoria, os implícitos (pré-construídos e discursos transversos) etc. Em outras palavras, não se preocupar apenas com o conteúdo epistemológico em si dos textos de/sobre Mattoso, se pertinentes ou não para tratar dos fenômenos linguísticos descritos por Mattoso e se podem ser aplicados a outros fenômenos, mas compreender o papel dos diferentes elementos que excedem à textualidade na construção do pensamento mattosiano; 
Roberto Leiser Baronas; Samuel Ponsoni. Uma análise de discurso de base enunciativa: notas de leitura sobre o percurso epistemológico de Dominique Maingueneau.

b) $\mathrm{Na}$ análise a ser empreendida, não serão mais apenas as obras que articulam os conceitos às escolas em que foram forjados, que estarão no centro das preocupações de uma história e filosofia da linguística, mas o discurso da linguística, apreendido como rede de gêneros do discurso muito variados, que tratam das obras de Mattoso Câmara: de prefácios, de comentários, de advertências de suas obras, de orelhas, de artigos e de tese e dissertação que discutem o legado desse autor para a linguística produzida no Brasil etc.;

c) A análise refletirá sobre o discurso da linguística produzida por Mattoso Câmara ele-mesmo e por outros autores que o dizem, colocados em relação com outros tipos de discurso, ou seja, em relação às suas diferentes maneiras de inscrição no interdiscurso.

Como se pôde constatar nas linhas precedentes, o trabalho de Dominique Maingueneau, reescrito aqui, em algumas de suas ideias-força, ou como diz o próprio Maingueneau, em algumas das suas “convicções sobre o discurso" possui uma heurística positiva, que busca dar conta não somente dos corpora clássicos da Análise de Discurso, mas, sobretudo, de novos corpora, novas textualidades, colocando questões pertinentes para os analistas e para o campo do discurso.

\section{Referências}

AMOSSY, R. O ethos na intersecção das disciplinas: retórica, pragmática, sociologia dos campos. In: AMOSSY, R. (Org.). Imagens de si no discurso: a construção do ethos. São Paulo: Contexto, 2005.

DUCROT, O. O dizer e o dito. Campinas, SP: Pontes, 1987.

EGGS, E. Ethos aristotélico, convicção e pragmática moderna. In: AMOSSY, R. (Org.). Imagens de si no discurso: a construção do ethos. São Paulo: Contexto, 2012.

FOUCAULT, M. A ordem do discurso. Tradução de Laura Fraga de Almeida Sampaio. São Paulo: Loyola, 1996.

FONSECA, O. Mattoso Câmara Jr., pioneiro. Revista de Letras, Assis, v. 16, p. 203-210. 1974.

FRANÇA, A. Texto e contexto nos escritos linguísticos de Mattoso Câmara (19381954). Dissertação (Mestrado), Faculdade de Filosofia Letras e Ciências Humanas, Universidade de São Paulo, 1998.

LEITE, Y. Unidade e diversidade na obra de Mattoso Câmara Jr. Boletim da ABRALIN, v. 12, p. 180-192, 1991. 
LEITE, Y. O pensamento fonológico de Mattoso Câmara Jr. Boletim da ABRALIN, v. 7, p. 17-24, 1996.

MALDIDIER, D. A inquietação do discurso: (re)ler Michel Pêcheux hoje. Tradução de Eni Orlandi. Campinas, SP: Pontes, 2003.

MAINGUENEAU, D. Novas tendências em análise do discurso. Campinas, SP: UNICAMP, 1997.

MAINGUENEAU, D. O contexto da obra literária. São Paulo: Martins Fontes, 2001.

MAINGUENEAU, D. Gênese dos discursos. Tradução de Sírio Possenti. Curitiba, PR: Criar Edições, 2005a.

MAINGUENEAU, D. Ethos, cenografia, incorporação. In: AMOSSY, R. (Org.). Imagens de si no discurso: a construção do ethos. São Paulo: Contexto, 2005b.

MAINGUENEAU, D. Discurso literário. Tradução de Adail Sobral. São Paulo: Contexto, 2006a.

MAINGUENEAU, D. Contre Saint Proust ou la fin de la Littérature. Paris: Belin, 2006b.

MAINGUENEAU, D. Cenas da Enunciação. Organizado por Sírio Possenti e Maria Cecília Pérez de Souza-e-Silva, diversos tradutores. São Paulo: Parábola Editorial, 2008.

MAINGUENEAU, M Análise do discurso e literatura: problemas epistemológicos e institucionais. Tradução de Roberto Leiser Baronas e Samuel Ponsoni. Revista Linguasagem, $\quad \mathrm{n} . \quad 13,2010.2019$. <http://www.dl.ufscar.brlinguasagem/edicao13/art_01.php>. Acesso em: 2 maio 2019.

MAINGUENEAU, D. Doze conceitos em análise do discurso. São Paulo: Parábola Editorial, 2010.

MAINGUENEAU, D. Um réseau de concepts. (Entrevista concedida a Reindert Dhondt \& David Martens), Interférences littéraires / Literaire interferenties, n. 8, p. 203-221, maio 2012.

MAINGUENEAU, D. Discours et analyse du discours. Paris, FR: Armand Colin, 2014.

MAINGUENEAU, D. La philosophie comme instituition discursive. Paris, FR: LambertLucas, 2015a.

MAINGUENEAU, D. Discurso e análise do discurso. Tradução de Sírio Possenti. São Paulo, SP: Parábola Editorial, 2015b.

MATtOSO CÂMARA JR., J. Princípios de Linguística Geral. Rio de Janeiro: F. Briguet, 1941.

MATTOSO CÂMARA JR., J. Princípios de Linguística Geral. Rio de Janeiro: Livraria Acadêmica, 1954. 
Roberto Leiser Baronas; Samuel Ponsoni. Uma análise de discurso de base enunciativa: notas de leitura sobre o percurso epistemológico de Dominique Maingueneau.

MATTOSO CÂMARA JR., J. Ensaios machadianos (Língua e estilo). Rio de Janeiro: Livraria Acadêmica, 1962.

MATTOSO CÂMARA JR., J. Dicionário de Filologia e Gramática. 4ed- revisada e ampliada. São Paulo: J. Ozon Editor, 1970.

MATTOSO CÂMARA JR., J. História da Linguística. Petrópolis, RJ: Vozes, 1975.

MATTOSO CÂMARA JR., J. A Linguística brasileira. (1976). In: NARO, A. J. (Org.).

Tendências atuais da Linguística e da Filologia no Brasil. Francisco Alves Editora, 1976.

MATTOSO CÂMARA JR., J. História e estrutura da língua portuguesa. Rio de Janeiro: Padrão Editora, 1976b.

MATTOSO CÂMARA JR., J. Introdução às línguas indígenas brasileiras. Rio de Janeiro: Ao Livro Técnico, 1977.

MATTOSO CÂMARA JR., J. Contribuição à estilística portuguesa. Rio de Janeiro: Ao Livro Técnico, 1978.

MATTOSO CÂMARA JR., J. Problemas de linguística descritiva. Petrópolis, RJ: Vozes, 1994.

MATTOSO CÂMARA JR., J. Nomenclatura Gramatical (1960). In. UCHÔA, C. E. F. (Org.). Dispersos de Joaquim Mattoso Câmara Jr.. Rio de Janeiro: Lucerna, 2004a.

MATTOSO CÂMARA JR., J. As ideias gramaticais de João Ribeiro. (1961). In: UCHÔA, C. E. F. (Org.). Dispersos de Joaquim Mattoso Câmara Jr.. Rio de Janeiro: Lucerna, 2004b.

MATTOSO CÂMARA JR., J. Said Ali e a Língua Portuguesa. (1961). UCHÔA, C. E. F. (Org.). Dispersos de Joaquim Mattoso Câmara Jr.. Rio de Janeiro: Lucerna, 2004c.

MATTOSO CÂMARA JR., J. Antenor Nascentes e a filologia brasileira. (1966). UCHÔA, C. E. F. (Org.). Dispersos de Joaquim Mattoso Câmara Jr.. Rio de Janeiro: Lucerna, 2004d.

MATTOSO CÂMARA JR., J. Os estudos de português no Brasil. (1969). UCHÔA, C. E. F. (Org.). Dispersos de Joaquim Mattoso Câmara Jr.. Rio de Janeiro: Lucerna, 2004e.

MATTOSO CÂMARA JR., J. Os congressos internacionais de linguistas. (1972). In. UCHÔA, C. E. F. (Org.). Dispersos de Joaquim Mattoso Câmara Jr.. Rio de Janeiro: Lucerna, $2004 f$.

MATTOSO CÂMARA JR., J. Crônica Linguística. (1972). In. UCHÔA, C. E. F. (Org.). Dispersos de Joaquim Mattoso Câmara Jr.. Rio de Janeiro: Lucerna, 2004g.

MATTOSO CÂMARA JR., J. Língua e cultura. (1972). In. UCHÔA, C. E. F. (Org.). Dispersos de Joaquim Mattoso Câmara Jr.. Rio de Janeiro: Lucerna, 2004h. 
NARO, A. J.; REIGHARD, J. Bibliografia analítica de Joaquim Mattoso Câmara. In: NARO, A. J. (Org.). Tendências atuais da Linguística e da Filologia no Brasil. Francisco Alves Editora, 1976.

PÊCHEUX, M. Análise automática do discurso. In: GADET, F.; HAK, T. (Orgs.). Por uma análise automática do discurso. Campinas, SP: Editora da Unicamp. 1990, p. 61-161.

PÊCHEUX, M. Semântica e discurso: uma crítica à afirmação do óbvio. Campinas, SP: Editora da Unicamp, 1988.

PÊCHEUX, M. Leitura e memória. In: Análise do discurso: Michel Pêcheux (textos escolhidos por Eni Puccinelli Orlandi). Campinas, SP: Editora Pontes, 2011, p. 141-150.

PÊCHEUX, M. Papel da memória. In: ACHARD, P.; et al. Papel da memória. Campinas, SP: Editora Pontes, 1999, p.49-57.

RODRIGUES,A. D. A obra científica de Mattoso Câmara Jr., Caderno de Estudos Linguísticos, Campinas, SP: IEL - UNICAMP, n. 6, 1980. Disponível em: <https://periodicos.sbu.unicamp.br/ojs/index.php/cel/article/view/8636654>. Acesso em: 2 maio 2019. DOI: https://doi.org/10.20396/cel.v6i0.8636654

RODRIGUES, K. C. Por uma análise do discurso literário: funcionamento da autoria em Oscar Wilde e construção de imagens de autor. Tese (Doutorado). Programa de PósGraduação em Estudos Linguísticos, Universidade Federal de Uberlândia, 2014.

SÉRIOT, P. Analyse do discours politique soviétique. Revue Persée, v. 57, n. 2, 1985.

UCHÔA, C. E. F.Os estudos e a carreira de Joaquim Mattoso Câmara Jr. In: UCHÔA, C. E. F. (Org.). Dispersos de J. Mattoso Câmara. Rio de Janeiro. Editora da Fundação Getúlio Vargas, 1972.

UCHÔA, C. E. F. Mattoso Câmara Jr. e os estudos linguísticos no Brasil. Boletim da ABRALIN, v. 7, p.9-15, 1986.

UCHÔA, C. E. F. (Org.). Dispersos de J. Mattoso Câmara: nova edição revisada e ampliada. Lucerna, 2004a.

VALlE, R. Mattoso Câmara e a História da Língua Portuguesa. Confluência, n. 29-30, 2005. Disponível em:<http://llp.bibliopolis.info/confluencia/pdf/1068.pdf $>$. Acesso em: 2 maio 2019.

Recebido em: 5 de maio de 2019

Aceito em: 4 de junho de 2019 